\title{
Efficient Titanium-Catalyzed Synthesis of Pyrazolo[4,3-f]quinolinones
}

\author{
SAMAN DAMAVANDI ${ }^{*}$ and REZA SANDAROOS \\ Department of Chemistry, Sarvestan Branch, Islamic Azad University, Sarvestan, Iran \\ saman_damavandi@yahoo.com
}

Received 8 May 2012 / Accepted 18 May 2012

\begin{abstract}
An efficient, titanium-catalyzed synthesis of pyrazolo[4,3- $f$ ]quinolinones was accomplished by the one-pot condensation reactions of 1,3-indanedione, aromatic aldehydes and 5-aminoindazole in toluene in the presence of bis[7-methyl-2-anilinotropone] Ti complex.
\end{abstract}

Keywords: Pyrazolo[4,3-f]quinolinone, One-pot, Catalyst, Synthesis

\section{Introduction}

The organic compound contains pyrazoline moiety, which have been explored for the emitting layer and hole transporting material in the OLEDs ${ }^{1,2}$. He et al. have studied the photo-physical properties of pyrazolo[3,4-b] quinoline (PAQ) derivatives, which could be the dopants in the polymer-LED materials ${ }^{3}$.

Pyrazolo[3,4- $f$ ] quinoline derivatives are a novel class of immunostimulant with potent in vivo effects in a murine infection model $^{4,5}$. Studies in side-chain structure-activity relationships (SAR), formulation issues and injection site toleration have been addressed, and compounds suitable for extensive in vivo evaluation have been identified ${ }^{6}$. Although there are a few reports on the synthesis of pyrazoloquinoline compounds $\mathrm{s}^{7-14}$, the synthesis of such compounds is still of great significance.

A recent survey of the literature revealed that the synthesis of the pyrazolo[4,3- $f$ ] quinoline derivatives have been limited to either by multi-step reactions or by twocomponent condensations under heating conditions with relatively long reaction times and limited structural diversity of target molecules ${ }^{15-18}$. As a result, the development of a simple, straightforward and efficient methods for synthesis of pyrazolo[4,3- $f$ ] quinoline derivatives is strongly desirable. Although recently, only Shi and coworkers reported microwaveassisted one-pot synthesis of pyrazolo[4,3- $f$ ]quinolines ${ }^{19}$, to the best of our knowledge, onepot synthesis of pyrazolo[4,3-f] quinolinones, that may provide new classes of biological active for biomedical screening, using bis[7-methyl-2-anilinotropone] Ti complex has been never reported up to now. In the continuation of our general interest in the synthesis of heterocyclic compounds by the MCR reactions ${ }^{20}$, Herein, we wish to report the details of this study (Scheme 1). 


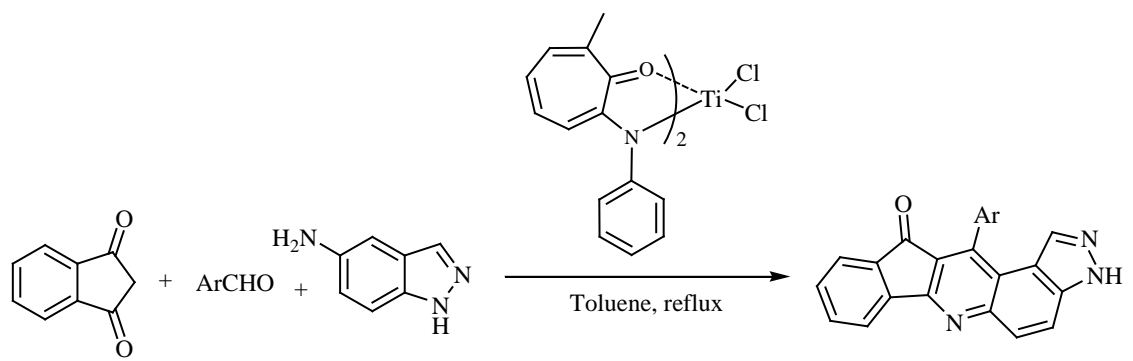

Scheme 1

\section{Experimental}

Chemicals were either prepared in our laboratories or purchased from Merck, Fluka and Aldrich Chemical Companies. All yields refer to isolated products. IR spectra were recorded as $\mathrm{KBr}$ disk on a Shimadzu-IR 470 spectrophotometer and the results are report in $\mathrm{cm}^{-1}$. ${ }^{1} \mathrm{H}$ NMR spectra was recorded on a Bruker $400-\mathrm{MHz}$ spectrometer in DMSO- $d_{6}$ as the solvent, TMS was used as the internal standard and the results are reported in ppm. Analytical thin layer chromatography (TLC) was performed on pre-coated silica gel plates (60F-254). Elemental analyses were performed on Thermo Finnigan EA1112 elemental analyser. The procedure for synthesis of the catalyst has been reported elsewhere ${ }^{21}$.

\section{General procedure for synthesis of pyrazolo[4,3-f]quinolinones}

In a round bottom flask purged by nitrogen gas already, a mixture of 1,3-indanedione (1 mmol), aromatic aldehyde $(1 \mathrm{mmol})$ and 5 -aminoindazole $(1 \mathrm{mmol})$ in the presence of bis[7-methyl-2-anilinotropone] Ti complex $(0.1 \mathrm{mmol})$ was stirred under reflux condition in dried toluene. The progress of the reactions were monitored by TLC (ethylacetate: $n$-hexane 1:5). Upon the completion of the reaction, the heterogeneous catalyst was separated from the mixture. After cooling to room temperature, the resulting precipitate was filtered off and washed with water. The solid was dried and crystallized from $\mathrm{H}_{2} \mathrm{O}$ :EtOH (1:3) to obtain the pure desired product in high to excellent yield.

12-(4-Nitrophenyl)-3,11-dihydroindeno[1,2-b]pyrazolo[4,3-f] quinolin-11-one (4b) IR: $\left(\mathrm{KBr}, v \mathrm{~cm}^{-1}\right)$ : 3410, 1685, 1645, 1510, 1445, 1325, 1265, 1211, 935. ${ }^{1} \mathrm{H}$ NMR $\left(100 \mathrm{MHz}, \mathrm{DMSO}-\mathrm{d}^{6}\right): \delta 11.55$ (s, 1H, NH), 8.35 (d, 2H, $\left.J=7.5 \mathrm{~Hz}, \mathrm{ArH}\right), 7.95-7.70$ (m, 5H, ArH), 7.65-7.35 (m, 3H, ArH), 6.70 (s, $1 \mathrm{H}, \mathrm{Ar}$ ). Anal. Calcd. for $\mathrm{C}_{23} \mathrm{H}_{12} \mathrm{~N}_{4} \mathrm{O}_{3}$ : C, 70.41; H, 3.08; N, 14.28; Found: C 65.47, H 3.18, N 14.10.

\section{2-(4-Bromophenyl)-3,11-dihydroindeno[1,2-b]pyrazolo[4,3-f]quinolin-11-one (4c)}

IR: $\left(\mathrm{KBr}, v \mathrm{~cm}^{-1}\right)$ : 3325, 1695, 1665, 1520, 1465, 1285, 1112, 957, 754. ${ }^{1} \mathrm{H}$ NMR $(100 \mathrm{MHz}$, DMSO-d $\left.d^{6}\right): \delta 11.40(\mathrm{~s}, 1 \mathrm{H}, \mathrm{NH}), 7.84(\mathrm{~d}, 2 \mathrm{H}, J=7.5 \mathrm{~Hz}, \mathrm{ArH}), 7.75-7.55$ (m, 4H, ArH), 7.45-7.20 (m, 4H, ArH), 6.65 (s, $1 \mathrm{H}, \mathrm{ArH})$. Anal. Calcd. for $\mathrm{C}_{23} \mathrm{H}_{12} \mathrm{BrN}_{3} \mathrm{O}$ : C, 64.81; $\mathrm{H}$, 2.84; N, 9.86 Found: C 63.84, H 2.98, N 10.02.

\section{2-(4-methoxyphenyl)-3,11-dihydroindeno[1,2-b]pyrazolo[4,3-f]quinolin-11-one (4e)}

IR: $\left(\mathrm{KBr}, v \mathrm{~cm}^{-1}\right)$ : 3353, 1704, 1632, 1557, 1495, 1422, 1268, 1088, 954. ${ }^{1} \mathrm{H}$ NMR (100 MHz, DMSO-d $\left.d^{6}\right): \delta 12.40$ (s, 1H, NH), 8.05-7.70 (m, 5H, ArH), 7.65-7.45 (m, 4H, Ar), 7.25 (d, 2H, $J=7.3 \mathrm{~Hz}, \mathrm{ArH}$ ), 6.95 (d, 2H, $J=7.3 \mathrm{~Hz}, \mathrm{ArH}), 6.51$ (s, 1H, ArH), 3.65 (s, 3H, $\mathrm{CH}_{3} \mathrm{O}$ ). Anal. Calcd. for $\mathrm{C}_{24} \mathrm{H}_{15} \mathrm{~N}_{3} \mathrm{O}_{2}$ : C, 76.38; H, 4.01; N, 11.13; Found: C 74.37, H 4.11, N 11.26. 


\section{2-(2-Thienyl)-3,11-dihydroindeno[1,2-b]pyrazolo[4,3-f]quinolin-11-one (4i)}

IR: $\left(\mathrm{KBr}, v \mathrm{~cm}^{-1}\right)$ : 3372, 1721, 1744, 1662, 1445, 1352, 1212, 1088, 967, 810. ${ }^{1} \mathrm{H}$ NMR (100MHz, DMSO-d6): $\delta 12.45$ (s, 1H, NH), 8.10 (d, 3H, $J=5.2 \mathrm{~Hz}, \mathrm{ArH}), 7.88-7.65$ (m, 3H, ArH), 7.55-7.35 (m,3H, ArH), 6.50 (s, 1H, ArH). Anal. Calcd. for $\mathrm{C}_{21} \mathrm{H}_{11} \mathrm{~N}_{3} \mathrm{OS}$ : C, 76.38; H, 4.01; N, 11.13; Found: C 75.55, H 4.15, N 11.03.

\section{Results and Discussion}

Organometal catalysts are versatile catalysts which have been used in many various fields of organic chemistry. As a result of ligand-oriented catalyst design research in our laboratories, we have developed a new family of group 4 transition metal complexes bearing two aminotropone chelate ligands ${ }^{21}$.

Choosing an appropriate solvent is of crucial importance for successful synthesis. To optimize the reaction solvent, the reaction of 4-nitrobenzaldehyde, 1,3-indanedione and 5 -aminoindazole was carried out in different organic solvents containing toluene, benzene, ethylacetate, 1,2-dichloroethane and acetonitrile at reflux condition. The results are summarized in Table 1. It was shown that the reactions in refluxing toluene afforded the best results. Therefore, it was chosen as the solvent for the subsequent reactions. The catalyst, bis[7-methyl-2-anilinotropone] $\mathrm{Ti}$ complex, efficiently promoted the multicomponent reactions and as illustrated in Table 2, a various series of pyrazolo[4,3- $f$ ] quinolinone derivatives were synthesized in high to excellent yields.

In order to modify the pyrazolo[4,3- $f$ ]quinoline ring, heterocyclic aldehydes were also employed and the reactions of furan-2-carbaldehyde or thiophene-2-carbaldehyde, in combination with 1,3-indanedione and 5-aminoindazole were examined. The results revealed that this protocol could be applied not only to aromatic aldehydes with either electronwithdrawing or electron-donating groups but also to heterocyclic aromatic aldehydes (Entries 8,9). Beside the high efficiency of the catalyst, due to the heterogeneous nature of the catalyst, the catalyst was simply filtered off which provides convenient work-up procedure.

Table 1. Influence of solvent on the synthesis of 12-(4-nitrophenyl)-3,11-dihydroindeno [1,2-b]pyrazolo[4,3-f]quinolin-11-one

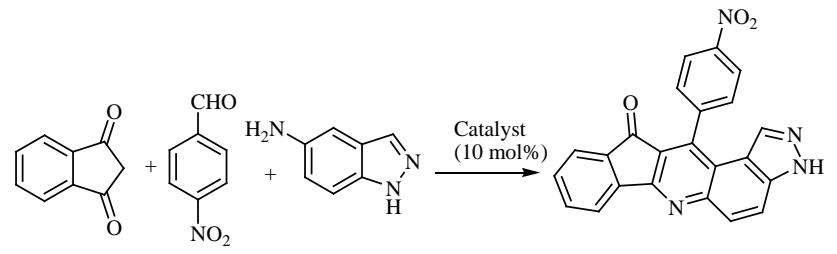

\begin{tabular}{cccccc}
\hline Solvent & Toluene & Benzene & $\mathrm{C}_{2} \mathrm{H}_{4} \mathrm{Cl}_{2}$ & EtOAc & $\mathrm{CH}_{3} \mathrm{CN}$ \\
\hline Isolated Yield $^{\mathrm{a}}$ & 91 & 77 & 70 & 65 & 53 \\
\hline
\end{tabular}

a) All the reactions were carried out at reflux condition for 5 h. Reaction conditions: 4-nitrobenzaldehyde (1.0 equiv), 1,3-indanedione (1.0 equiv) and 5-aminoindazole (1.0 equiv), catalyst (0.1 equiv)

The possible mechanism may proceed via a sequence reaction of condensation, addition, cyclization and dehydration (Scheme 2). First, the condensation between aromatic aldehyde and 1,3-indandione leads to intermediate A; Michael-type addition of 5-aminoindazole to $\mathbf{A}$ gives $\mathbf{B}$, which upon intermolecular cyclization and dehydration furnishes the corresponding pyrazolo[4,3- $f$ ]quinolinone product. 
Table 2. Results of multicomponent synthesis of pyrazolo[4,3- $f$ ]quinolinone derivatives

\begin{tabular}{ccccc}
\hline Entry $^{\mathrm{a}}$ & $\mathrm{Ar}$ & Product & Time, $\mathrm{h}$ & ${\text { Yield, }{ }^{\mathrm{a}}}^{\mathrm{a}}$ \\
\hline 1 & $\mathrm{C}_{6} \mathrm{H}_{5}$ & $\mathbf{4 a}$ & 5.5 & 88 \\
2 & $4-\mathrm{NO}_{2}-\mathrm{C}_{6} \mathrm{H}_{4}$ & $\mathbf{4 b}$ & 4.5 & 91 \\
3 & $4-\mathrm{Br}^{-} \mathrm{C}_{6} \mathrm{H}_{4}$ & $\mathbf{4 c}$ & 5 & 93 \\
4 & $4-\mathrm{CH}_{3}-\mathrm{C}_{6} \mathrm{H}_{4}$ & $\mathbf{4 d}$ & 4.5 & 90 \\
5 & $4-\mathrm{CH}_{3} \mathrm{O}_{6}-\mathrm{C}_{6} \mathrm{H}_{4}$ & $\mathbf{4 e}$ & 5 & 92 \\
6 & $4-\mathrm{NMe}_{2} \mathrm{C}_{6} \mathrm{H}_{4}$ & $\mathbf{4 f}$ & 5 & 85 \\
7 & 3- $\mathrm{NO}_{2}-\mathrm{C}_{6} \mathrm{H}_{4}$ & $\mathbf{4 g}$ & 5 & 91 \\
8 & 2-Furanyl & $\mathbf{4 h}$ & 6 & 86 \\
9 & 2-Thienyl & $\mathbf{4 i}$ & 6 & 88 \\
\hline
\end{tabular}

a) Isolated yields

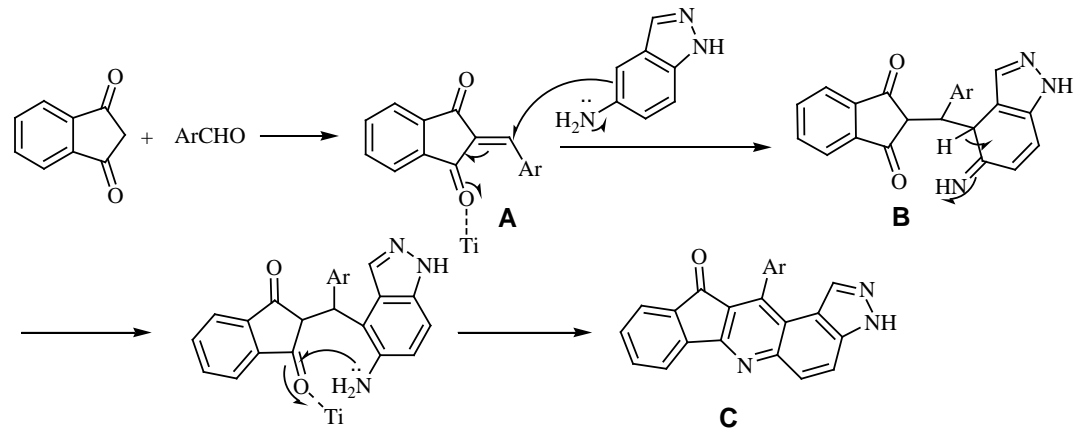

Scheme 2

\section{Conclusion}

In summary, we have provided a practical and efficient method for the synthesis of pyrazolo[4,3-f]quinolinone derivatives. This one-pot MCR offers the advantages of good yields, one step, simple workup procedure, broader substrate scope, operational simplicity, and cleanliness of the reactions.

\section{References}

1. Lu Z, Jiang Q, Zhu W, Xie M, Hou Y, Chen X and Wang Z, Synth Met., 2000, 111, 465.

2. Gao Z Q, Lee C S, Bello I, Lee S T, Wu S K, Yan Z L and Zhang X H, Synth Met., 1999, 105, 141.

3. Lu Z, Jiang Q, Zhu W, Xie M, Hou Y, Chen X, Wang Z, Zou D and Tsutsui T, Synth Met., 2000, 111, 425.

3. He Z, Milburn G H W, Baldwin K J, Smith D A, Danel A and Tomasik P, J Lumin., 2000, 86, 1.

4. $\quad$ Blecha F, Vet Med., 1990, 231.

5. Moyer M P, Weber F H, Canning P C, Gross J L and Saint F R, Bioorg Med Chem Lett., 1993, 3, 1379.

6. Kawakami T, Uehata K and Suzuki H, Org Lett., 2000, 2, 413.

7. Mac M, Uchacz T, Wróbel T, Danel A and Kulig E, J Fluoresc., 2010, 20, 525.

8. Chaczatrian K, Chaczatrian G, Danel A and Tomasik P, ARKIVOC, 2001, (vi), 63.

9. Tu S J, Wu S S, Zhang X H, Han Z G, Cao X D and Hao W J, Synth Commun., 2010, 40, 1057. 
10. Sergei L B, Konstantin I. K, Anna A M, Igor F P, Sergei Y S, Martin R B, Svetlana B L, Andrei S B and Natalya M B, Org Biomol Chem., 2005, 3, 932.

11. Afghan A, Baradarani M M and Joule J A, Arkivoc, 2009, (ii), 20.

12. Paul S, Gupta M, Guptaa R and Loupy A, Tetrahedron Lett., 2001, 42, 3827.

13. Elkholy Y M, Molecules, 2007, 12, 361.

14. Wu L Q, Dong R Y, Yang C G and Yan F L, J Chin Chem Soc., 2010, 57, 19.

15. Plaskon A S, Ryabukhin S V, Volochnyuk D M, Gavrilenko K S, Shivanyuk A N and Tolmachev A A, J Org Chem., 2008, 73, 6010.

16. Carotti A, Altomare C, Savini L, Chiasserini L, Pellerano C, Mascia M P, Maciocco E, Busonero F, Mameli M, Biggio G and Sanna E, Bioorg Med Chem., 2003, 11, 5259.

17. Ajami A M, Chem Abstr., 2008, 148, 239202.

18. Ajami A M, Chem Abstr., 2008, 148, 529475.

19. Shi F, Zhang S, Wu S S, Gao Y and Tu S J, Mol Divers., 2011, 15, 497.

20. Damavandi S and Sandaroos R, Heterocycl Commun., 2011, 17, 121.

21. Sandaroos R, Damavandi S and Farhadipour A, Macromol Chem Phys., 2010, 211, 2339. 